\title{
РЕАЛИЗАЦИЯ ГОСУДАРСТВЕННЫХ ПРОГРАММ ПО ПОВЫШЕНИЮ УРОВНЯ ОБЕСПЕЧЕННОСТИ НАСЕЛЕНИЯ РОССИИ ЖИЛЬЕМ
}

\author{
(C) 2020 Салахова Зарина Ринатовна \\ ассистент кафедры управления человеческими ресурсами \\ Института управления, экономики и финансов \\ Казанский (Приволжский) федеральный университет, Россия, Казань \\ E-mail: zarinasalakhova@mail.ru
}

В статье осуществляется попытка проанализировать развитие государственных программ в области жилищной политики в нашей стране, начиная со времен Советского союза до настоящего времени, а также основные показатели их эффективности.

Ключевые слова: обеспеченность жильем, жилищные программы, национальные проекты, государственные программы, доступное и комфортное жилье, приоритетные национальные проекты.

Обеспеченность жильем является базовой потребностью каждого человека. В соответствии со статьей 25 Всеобщей декларации прав человека, любой человек имеет право на такой жизненный уровень, который необходим для поддержания здоровья и благосостояния его самого и его семьи, включая пищу, одежду, жилище, медицинский уход и необходимое социальное обслуживание [2].

В условиях пандемия COVID-19 проблемы обеспеченности жильем становятся все более актуальными. Так в октябре 2020 года генеральный секретарь ООН Антониу Гутерреш в докладе «Города мира 2020» заявил, что пандемия COVID-19 нарушила жизнь людей и экономику мира, обнажив многочисленные проблемы человечества. Особо уязвимыми оказались люди, проживающие в городах с отсутствием планирования городской жизни, так борьба с вирусом была обострена на территориях, где неравномерен доступ к качественному медицинскому обслуживанию, отсутствует доступное жилье, слабо развиты водоснабжение и санитария, транспортная инфраструктура неоднородна, а рабочие места нестабильны. Было отмечено, что только при наличии надлежащих мер политики и вспомогательных механизмов «жизнеспособные города с улучшенными жилищными условиями и инфраструктурой способны оправиться от разрушительных последствий бедствий, включая пандемии».

Одной из целей устойчивого развития, нацеленных на улучшение благосостояния и защиту нашей планеты, провозглашаемых ООН, являются устойчивые города и населенные пункты. Для достижения указанной цели поставлена задача по обеспечению к 2030 году всеобщего доступа к достаточному, безопасному и недорогому жилью, а также благоустройство трущоб [16]. Таким образом, задача по повышению обеспеченности жильем населения, является общечеловеческой и осознается во всем мире.

В России можно выделить несколько этапов по решению данного вопроса. Первую крупномасштабную жилищную программу можно отнести к периоду 1955-1965 гг. [16]. Так, 4 ноября 1955 года было принято постановление Центрально комитета КПСС и Совета министров СССР «Об устранении излишеств в проектировании и строительстве», положившее начало советскому минимализму, типовому проектированию, увеличению экономичности и скорости строительства. В постановлении указывались конкретные примеры излишеств и имена допустивших их архитекторов: «Особенно большие излишества были допущены архитектором Рыбицким в построенном доме по улице Чкалова, для отделки которого применены дорогостоящие материалы, сложные архитектурные украшения и декоративные аркады; при планировке квартир недопустимо завышены площади передних, коридоров и других вспомогательных помещений. Стоимость одного квадратного метра жилой площади в этом доме составляет 3400 рублей, что в два-три раза превышает стоимость жилой площади в экономично запроектированных домах» [3].

В 1956 году на XX съезде КПСС была поставлена задача ликвидировать жилищный дефицит за 20 лет. В 1957 году принято постановление ЦК 
КПСС и СМ СССР «О развитии жилищного строительства в СССР», которое закрепило официально сформировавшиеся к этому времени новые принципы строительства и архитектуры. В 1958 году эти принципы были отражены в новой редакции СНиП II-B.10-58 «Жилые здания».

Таким образом, несмотря на спорность новых принципов строительства с точки зрения архитектурной ценности, они дали мощный толчок к развитию массового строительства. Так за период 1957-1970 годов было построено более 400 млн. кв.м пятиэтажек. Для сравнения общая площадь жилищного фонда города Москвы по данным Росстата на 2019 год составляет 245,8 млн.кв.м. [3].

Следующая масштабная программа решения проблемы жилья реализовывалась в период 1985-2000 гг. Эта программа предусматривала, что каждая семья будет обеспечена современными отдельной квартирой или домом. В процессе реализации данной программы развивались одновременно с государственными вложениями проекты с участием средств населения - строительство жилых кооперативных домов. Существовало использование средств предприятий и дифференцировались финансово-экономические льготы по различным категориям семей.

В рамках данной программы были достигнуты рекордные объема ввода жилья в России [7]:

- в 1986 году - 66,2 млн. кв.м.;

- в 1987 году - 75,8 млн. кв.М.;

- в 1988 году - 72,3 млн. кв.м.;

- в 1989 году - 70,4 млн. кв.м. [7]

В 1990 году реализация данной программы была приостановлена в связи с сокращением государственного участия и переходом к рыночным принципам экономики.

Третья программа в сфере жилья называлась «Жилище» и относилась к 1990-2000 гг. По мнению Фахрутдиновой Е.В. [12-14] при разработке приоритетного национального проекта «Доступное жилье» были выявлены следующие основные проблемы российского жилищного рынка:

- большинство людей нуждаются в жилье, но не могут себе позволить его покупку;

- в России отсутствует эффективная система долгосрочного жилищного кредитования;

- нынешних объемов жилищного строительства не хватает для удовлетворения потребностей населения;
- качество жилищных и коммунальных услуг остается очень плохим, а уровень износа коммунальной инфраструктуры - высоким;

- социальное жилье и жилье для инвалидов, ветеранов и других категорий граждан выделется очень низкими темпами;

- граждане слабо защищены от махинаций при покупке и продаже жилья [13, с.77].

Для решения данных проблем Министерством регионального развития России совместно с Росстроем была разработана федеральная целевая программа «Жилище», которая является базовым механизмом реализации национального проекта [13, с.77-78], но, по нашему мнению, практических мер по реализации программы «Жилище» предпринято не было.

Началом следующего этапа решения жилищного вопроса можно назвать выступление Владимира Путина на встрече с членами Правительства, руководством Федерального Собрания и членами президиума Государственного совета 5 сентября 2005 года, где был обозначен курс государственной политики на инвестиции в человека и существенное повышение качества жизни. В отношении жилищной политики была обозначена задача - обеспечить к 2007 году значительный рост объемов жилищного строительства, не менее чем на одну треть к уровню 2004 года, развить формы ипотечного кредитования, обеспечить жильем военнослужащих и сотрудников правоохранительных систем, поддержка молодых семей.

С 1 января 2006 года в России началась реализация масштабных национальных проектов, среди которых национальный приоритетный проект «Доступное и комфортное жилье - гражданам России», ориентированный на 2006-2010 гг. Цель проекта была обозначена как формирование рынка доступного жилья и обеспечение комфортных условий проживания российских граждан. Одной из главных задач был рост объема жилищного строительства до 80 млн.кв.м до 2010 году. Достичь данного показателя в 2010 году не удалось, так по итогам 2009 года по данным Росстата показатель составил 64,1 млн.кв.м., по итогам 2010 года - 58,4 млн. Kв.M [4].

В 2010 году на заседании Совета по реализации приоритетных национальных проектов под председательством Д.А.Медведева были продлены сроки реализации национальных проектов, а также утверждены их основные параме- 
тры на период с 2011 по 2013 гг. В частности в 2010 году были утверждены новые документы государственного стратегического планирования - государственные программы. В рамках жилищного вопроса были утверждены программы: «Обеспечение доступным и комфортным жильем и коммунальными услугами граждан РФ» И «Доступная среда на 2011-2020 гг».

В 2012 году В.И.Путиным после вступления в должность президента РФ был подписан ряд указов, так называемые «майские указы», в которых содержались поручения Правительству РФ по достижению целевых показателей социально-экономического развития до 2020 года. В отношении жилищной политики был подписан Указ № 600 «О мерах по обеспечению граждан Российской Федерации доступным и комфортным жильем и повышению качества жилищно-коммунальных услуг» [11]. Среди поставленных задач можно выделить следующие:

- обеспечить до 2018 года увеличение количества выдаваемых ипотечных жилищных кредитов до 815 тысяч в год;

- обеспечить до 2018 года создание для граждан РФ возможности улучшения жилищных условий не реже одного раза в 15 лет;

- обеспечить до 2020 года предоставление доступного и комфортного жилья $60 \%$ российских семей, желающих улучшить свои жилищные условия.

Следующим этапом развития национальных проектов можно считать утверждение в 2016 году перечня из 11 основных направлений стратегического развития России до 2018 г. и до 2025 г. на заседании Совета по стратегическому развитию и приоритетным проектам. Так в 2018 году была сформирован новый национальный проект в отношении жилищного вопроса «Жилье и городская среда» сроком до 31.12.2024 [6]. Национальный проект включает 4 федеральных проекта:

- «Ипотека»- основная цель проекта состоит в создании возможностей для приобретения жилья гражданами по ипотечным кредитам менее 8\% к 2024 году. Следует отметить, что данная цель была достигнута даже раньше, так в апреле 2020 года началась государственная программа льготной ипотеки на новостройки со ставкой до $6,5 \%$.

- «Жилье» - основной целью проекта является строительство жилого фонда объемом не менее 120 млн. кв.м. ежегодно.

- «Обеспечение устойчивого сокращения непригодного для проживания жилищного фонда» - целью проекта является обеспечение устойчивого сокращения непригодного для проживания жилищного фонда, расселение к 31.12.2024 не менее 530,8 тыс человек, не менее чем с 9,56 млн.кв.м аварийного жилья.

- «Формирование комфортной городской среды» - цель проекта состоит в создании более комфортных условий для жителей городов, повысить индекс качества городской среды на 30\% [6].

Следует отметить, что последний федеральный проект смещает акцент только с обеспечения жильем населения, т.е. удовлетворения самых базовых потребностей человека, в сторону создания комфортной, красивой среды обитания. Таким образом, можно говорить о переходе на новый уровень социально-экономического развития. Люди теперь стремятся не просто иметь свою квартиру, а жить в районах с единой архитектурной застройкой, рядом с парком или сквером, иметь во дворе благоустроенные детские площадки и парковочные места. В рамках данного федерального проекта разработана методика формирования индекса городской среды, состоящая из 36 показателей, среди которых: доля населения, живущего в аварийном жилье, в общей численности населения, разнообразие жилой застройки, разнообразие услуг в жилой зоне, уровень озеленения и др. В целом, можно сказать, что в данном направлении Россия движется в соответствии с современными мировыми тенденциями.

В июле 2020 года был подписан указ о продлении национальных проектов до 2030 года, в частности в рамках жилищной политики осталась цель по увеличению объема жилищного строительства не менее чем до 120 млн.кв.м в год, а также улучшение жилищных условий не менее 5 млн. семей ежегодно [10].

Схематично развитие национальных проектов в жилищной области представлено на рис. 1 .

Анализируя основные целевые показатели национальных проектов, можно сказать, что одним из ключевых показателей повышения уровня обеспеченности жильем является объем жилищного строительства. Так за период с 2009 по 2019 год данный показатель вырос на 37\% с 64,1 до 88 млн.кв.м. в год [5].

Вторым показателем, используемым при оценке эффективности государственных программ, можно считать объем ввода жилья, статистические данные приведены в таблице 1. 


\begin{tabular}{|c|c|c|c|c|}
\hline 5 сентября 2005 года & & 1 января 2006 года & & 29 июля 2010 года \\
\hline $\begin{array}{c}\text { Совещание В.В.Путина по } \\
\text { вопросам по вопросам } \\
\text { повышения качества жизни } \\
\text { населения }\end{array}$ & $\rightarrow$ & $\begin{array}{l}\text { Начало реализации нацпроекта } \\
\text { «Доступное и комфортное жилье } \\
\text { гражданам России», 2006-2010 }\end{array}$ & $\rightarrow$ & $\begin{array}{c}\text { Продление нацпроекта до } 2013 \\
\text { года, утверждение новых } \\
\text { государственных программ }\end{array}$ \\
\hline 7 мая 2012 года & & 24 декабря 2018 года & & 21 июля 2020 года \\
\hline $\begin{array}{c}\text { Указ № } 600 \text { «О мерах по } \\
\text { обеспечению граждан РФ } \\
\text { доступным и комфортным } \\
\text { жильем...» }\end{array}$ & $\rightarrow$ & $\begin{array}{c}\text { Утверждение национального } \\
\text { проекта «Жилье и городская } \\
\text { среда», а также } 4 \text { федеральных } \\
\text { проектов. 2018-2024 }\end{array}$ & $\rightarrow$ & $\begin{array}{c}\text { Продление национального } \\
\text { проекта до } 2030 \text { года }\end{array}$ \\
\hline
\end{tabular}

Рис.1. Хронология развития нацпроектов жилищной области в России

Таблица 1. Объем ввода жилья в год, млн.кв.м [5].

\begin{tabular}{|c|c|c|c|c|c|}
\hline 2015 год & 2016 год & 2017 год & 2018 год & 2019 год & $\begin{array}{c}2020 \text { год } \\
\text { по сост. на } \\
01.11 .2020\end{array}$ \\
\hline 83,35 & 80,2 & 78,6 & 75,66 & 82,0 & 55,0 \\
\hline$+1,4 \% *$ & $-6 \%$ & $-2,1 \%$ & $-4,5 \%$ & $+8,4 \%$ & \\
\hline
\end{tabular}

*динамика относительно предыдущего года

Однако можно ли утверждать, что увеличение объемов жилищного строительства однозначно приводит к росту уровня обеспеченности населения страны жильем? Во времена СССР такая связь была очевидна, поскольку распределением жилой площади распоряжалось государство, и квартиры выдавали людям в порядке очереди. В условиях рыночной экономики ситуация меняется и появляются такие факторы, как доходы населения, их потребительская способность. Так, к примеру, в настоящее время, растет число людей, которые покупают квартиры на этапе старта продаж, с целью инвестирования. Такая политика инвестирования достаточно оправдана, в связи со снижением ставок по банковским вкладам, санкциями, вводимыми Евросоюзом и США, нестабильным курсом валюты, ограничениями Центрального банка России на покупку и продажи валюты, нестабильностью фондовых рынков. В данных условиях покупка недвижимости, в частности жилья, является наименее рискованной стратегией.

Так по различным оценкам, сделки, совершаемые на рынке жилья с целью инвестирования, составляют порядка $12 \%$.

Возвращаясь к показателям обеспеченности жильем населения, следует отметить размер общей площади жилых помещений, приходящейся на одного человека. Статистические данные представлены в таблице 2 [9].

Таким образом, за период 2009 по 2019 год рост общей жилой площади, приходящейся на одного жителя, составил около 18\%. Следует отметить, что показатель в 26,3 кв.м на одного

Таблица 2. Общая площадь жилых помещений, приходящаяся в среднем на одного жителя, кв.м. [9]

\begin{tabular}{|l|c|c|c|c|c|c|c|c|c|c|c|}
\hline & 2009 & 2010 & 2011 & 2012 & 2013 & 2014 & 2015 & 2016 & 2017 & 2018 & 2019 \\
\hline $\begin{array}{l}\text { Общая площадь жилых по- } \\
\text { мещений, приходящаяся в } \\
\text { среднем на одного жителя } \\
\text { (на конец года)- всего, м2 }\end{array}$ & 22,2 & 22,6 & 23,0 & 23,4 & 23,4 & 23,7 & 24,4 & 24,9 & 25,2 & 25,8 & 26,3 \\
\hline из нее: & & & & & & & & & & & \\
\hline в городской местности & 21,8 & 22,1 & 22,5 & 22,9 & 22, & 23,3 & 24,0 & 24,5 & 24,8 & 25,4 & 25,9 \\
\hline в сельской местности & 23,4 & 24,0 & 24,5 & 24,8 & 24,7 & 25,0 & 25,6 & 26,2 & 26,6 & 26,9 & 27,3 \\
\hline
\end{tabular}


жителя в 2019 году не достигает нормы, установленной российском законодательством в 33 кв.м. на человека [15]. Для сравнения в Германии средняя обеспеченность жильем составляет 39 кв.м., в США - 70 кв.м. в Польше -25 кв.м, в Турции - 17 кв.м [8].

Таким образом, можно сделать вывод, что в России реализуется масштабная государственная политика в отношении повышения уровня обеспеченности населения жильем и повышения качества жизни. Государственные программы, реализуемые в данном направлении, дают свои результаты, однако при оценке их эффективности необходимо применять ряд показателей, которые помогают сформировать целостную картину, а не руководствоваться лишь одни каким-то индикатором.

\section{Библиографический список}

1. Бехметьева Ю.М. Жилищная обеспеченность как фактор уровня жизни и пути ее повышения// диссертация ... кандидата экономических наук: 08.00.05/ Москва. - 2004.-137с.

2. Всеобщая декларация прав человека// Режим доступа https://www.un.org/ru/documents/decl_conv/ declarations/declhr.shtml свободный (дата обращения 22.09.2020)

3. Документ, который изменил всё. Главное о Постановлении «Об устранении излишеств...»// Режим доступа https://strelkamag.com/ru/article/dokument-kotoryi-izmenil-vsyo свободный (дата обращения 22.08.2020)

4. История нацпроектов в России// Режим доступа https://tass.ru/info/6101471 свободный (дата обращения 15.10.2020)

5. Мониторинг объемов жилищного строительства// Режим доступа https://minstroyrf.gov.ru/trades/ zhilishnaya-politika/8/?sphrase_id=1130529 свободный (дата обращения 15.09.2020)

6. Национальный проект «Жилье и городская среда»// Режим доступа https:/национальныепроекты.рф/ projects/zhile-i-gorodskaya-sreda свободный (дата обращение 09.09.2020)

7. Россия сравнялась с РСФСР по объемам жилищного строительства//Газета «Ведомости» от 30.08.2013/ Режим доступа https://www.vedomosti.ru/realty/articles/2013/08/30/rossiya-dostigla-sovetskih-tempovzhilischnogo-stroitelstva свободный (дата обращения 12.10.2020)

8. Россияне обеспечены жильём лучше, чем жители многих стран// Газета «Время и деньги» от 25.10.2019/ Режим доступа https:/www.e-vid.ru/obschestvo/251019/rossiyane-obespecheny-zhilyom-luchshe-chem-zhitelimnogikh-stran свободный (дата обращения 12.10.2020)

9. Росстат/ Режим доступа https://rosstat.gov.ru/bgd/regl/b12_04/isswww.exe/Stg/d06/2-01.htm свободный (дата обращения 11.10.2020)

10. Указ Президента РФ от 21 июля 2020 г. N 474 «О национальных целях развития Российской Федерации на период до 2030 года» // Режим доступа http://publication.pravo.gov.ru/Document/View/0001202007210012 свободный (дата обращения 12.08.2020)

11. Указ Президента РФ от 07 мая 2012 г № 600 «О мерах по обеспечению граждан Российской Федерации доступным и комфортным жильем и повышению качества жилищно-коммунальных услуг»// Режим доступа http://kremlin.ru/acts/bank/35264 свободный (дата обращения 12.08.2020)

12. Фахрутдинова Е.В. Практика реализации национальных программ в сфере жилищного строительства// Вестник Московского университета МВД России. 2008. № 6. С. 104-107.

13. Фахрутдинова Е. В. Зарубежный опыт реализации национальных программ в сфере жилищного строительства// Экономические науки. 2008. № 49. С. 74-78.

14. Фахрутдинова E.В. Качество жизни населения в системе социально-экономических отношений (институциональный подход) // диссертация на соискание ученой степени доктора экономических наук / Казанский финансово-экономических институт. Казань, 2010.-420с.

15. Федеральный закон от 30.12.2012 № 283-Ф3 «О социальных гарантиях сотрудникам некоторых федеральных органов исполнительной власти и внесении изменений в отдельные законодательные акты Российской Федерации. ст.7.

16. Цели в области устойчивого развития// Режим доступа https://www.un.org/sustainabledevelopment/ru/cities/ свободный (дата обращение 29.09.2020) 